\title{
Green and Efficient Modification of Grape Seed Oil to Synthesize Renewable Monomers
}

\author{
Caroline Gaglieri, ${ }^{\oplus a}$ Rafael T. Alarcon, ${ }^{\oplus a}$ Aniele de Moura, ${ }^{\circledR b}$ Raquel Magri, ${ }^{\oplus a}$ \\ Luiz C. da Silva-Filho ${ }^{\circledR c}$ and Gilbert Bannach ${ }^{\circledR *, a}$ \\ ${ }^{a}$ Laboratório de Materiais Poliméricos, Faculdade de Ciências, Departamento de Química, \\ Universidade Estadual Paulista “Júlio de Mesquita Filho" (Unesp), 17033-260 Bauru-SP, Brazil \\ ${ }^{b}$ Laboratório de Análise Térmica e Química no Estado Sólido, Faculdade de Ciências, \\ Departamento de Química, Universidade Estadual Paulista “Júlio de Mesquita Filho” (Unesp), \\ 17033-260 Bauru-SP, Brazil \\ 'Laboratório de Sínteses Orgânicas e Processos, Faculdade de Ciências, Departamento de Química, \\ Universidade Estadual Paulista “Júlio de Mesquita Filho"(Unesp), 17033-260 Bauru-SP, Brazil
}

\begin{abstract}
Grape seed is a waste product from the wine and juice industries. However, vegetable oil can be extracted from it, which is a renewable chemical with a huge potential application after chemical modifications, such as epoxidation and maleinization processes. This paper therefore deals with the use of grape seed oil, to produce its epoxidized and maleinized derivatives. Both derivatives were synthesized in order to improve the conversion (99.4\%), yield (98.9\%) and selectivity $(99.5 \%)$ values, as well as to decrease the reaction time ( $3 \mathrm{~h}$ ) using cleaner energy sources and heterogeneous catalysts, which can be used $4 \times$ without regeneration and obtaining similar conversion and yield values, and at least $5 \times$ keeping high selectivity. Based on the characterization results, both grape seed oil derivatives may be applied in different fields, including polymer chemistry as a monomer, coating, and paint. In addition, they can be an option to industries that use petrochemical derivatives as precursors.
\end{abstract}

Keywords: renewable chemicals, maleinization reaction, epoxidized derivatives, microwave synthesis, Amberlite-IR120 reusability

\section{Introduction}

Food industrial wastes have increased worldwide, and consequently large amounts of wastes are just discarded without further use. However, these wastes can be applied in the chemistry and material fields as renewable/sustainable sources. Fruit/plant peel and seeds are the main food wastes; however, from the peel, renewable chemicals can be extracted such as cellulose and pectin. From the seed, the major product is the vegetable oil (triglycerides). ${ }^{1,2}$

In 2019, Brazil produced approximately 1.5 million tons of grape, while the global grape production was about 80 million tons in year before. ${ }^{3-5}$ In addition, $57 \%$ of global production was used in wine and juice industries, which generates about $20 \%$ of final waste. ${ }^{4,6}$ Each $100 \mathrm{~kg}$ of waste contains $25 \mathrm{~kg}$ of seeds which has $14-20 \%$ extractable

*e-mail: gilbert.bannach@unesp.br vegetable oil. ${ }^{1,7}$ Grape seed oil (GSO) has greater quantity of linoleic acid (72-76\%) than sunflower oil (60-62\%), safflower oil (70-72\%), corn oil (52\%), and soybean oil $(55 \%) .{ }^{1}$ Furthermore, GSO contains a greater quantity of tocopherol, which changes according with the variety and extraction methods. ${ }^{2,8}$

Vegetable oils have received great attention in recent studies such as potential alternatives to diesel fuels, health care products, drug delivery processes, food applications, antibacterial activity, and alternative to mineral waxes. . $^{914}$ Most of these applications demand some chemical modification of the vegetable oil structure aiming to decrease its viscosity, or even increase the molecule reactivity. In the last one, the modified vegetable oil can be applied as monomers in polymer synthesis, lubricants, coatings, and adhesives. ${ }^{15-19}$ These modifications can be performed using several types of reaction, resulting in products with different properties and dissimilar reactivity. 
Based on the large application of modified vegetable oil, its properties after chemical modification should be understood and compared.

Therefore, in this work two different and independent reactions (epoxidation and maleinization) were performed in GSO; thereafter, the products were characterized, and their properties were compared. These reactions were chosen due to the epoxidation process of some oils (linseed and soybean) are used in industrial scale (most of them under homogeneous conditions), which is an important reaction. However, most of papers in literature exhibit products with non-complete yield, ${ }^{20-23}$ demanding elevated time reaction, ${ }^{18,20,23,24}$ or homogeneous catalyst, ${ }^{21,24,25}$ or even show indicative of parallel reactions..$^{24,26}$ Hence, a reaction must be executed to achieve high yield of double bonds into epoxy rings in shorter time, using heterogeneous catalyst and consequently demanding less energy consumption in industry. On the other hand, the maleinization of some vegetable oils have been described in literature ${ }^{27-30}$ (laboratory scale), without determination of important properties such as density and viscosity, which could be a lack in the transfer to industrial scale. This reaction is described especially for soybean, linseed and tung oils; ${ }^{27-31}$ thus, it is important to study this reaction for other oils.

In addition, the use of vegetable oils for monomers production agrees with the $7^{\text {th }}$ Principle of Green Chemistry (related to the use of renewable feedstocks) and with the $1^{\text {st }}$ Principle of Green Engineering (utilization of materials and energy non-hazardous as possible). The synthesis processes used in this work also followed the $2^{\text {nd }}$ (atom economy; for maleinization), $6^{\text {th }}$ (design for energy efficiency), and $9^{\text {th }}$ (catalyst utilization; epoxidation reaction) Principles of Green Chemistry, ${ }^{32}$ as well as the $3^{\text {rd }}$ (decrease the energy and materials consumption in separation and purification steps), and $4^{\text {th }}$ (maximization of energy, time, mass and space) Principle of Green Engineering. ${ }^{33}$

Hence, this work aims to use the GSO, which is a promising renewable source, as a raw material in two independent reactions providing renewable compounds. Furthermore, this work presents a deep characterization for both compounds, as well as a comparison between their physic-chemical properties.

\section{Experimental}

Materials

The reactants maleic anhydride (MA, > 99.0\%, Sigma-Aldrich, Cotia, Brazil), toluene (99.5\%, SigmaAldrich, Cotia, Brazil), acetone (99.5\%, Sigma-Aldrich, Cotia, Brazil), hydrogen peroxide $\left(\mathrm{H}_{2} \mathrm{O}_{2}, 50\right.$ wt.\%, Synth,
Diadema, Brazil), acetic acid (AA, 99 wt.\%, SigmaAldrich, Cotia, Brazil), magnesium sulfate anhydrous $\left(\mathrm{MgSO}_{4}, 98.0 \%\right.$, Sigma-Aldrich, Cotia, Brazil), sodium carbonate $\left(\mathrm{Na}_{2} \mathrm{CO}_{3},>99.0 \%\right.$, Sigma-Aldrich, Cotia, Brazil), Amberlite-IR120 (98\%, Sigma-Aldrich, Cotia, Brazil), and GSO (batch code: SU061/05; leaking data: 04/2019 Mundo dos Óleos, Cruzeiro, Brazil), perchloric acid $\left(\mathrm{HClO}_{4}, 70\right.$ wt.\%, Sigma-Aldrich, Cotia, Brazil), potassium hydrogen phthalate $(\mathrm{KPH},>99.5 \%$, SigmaAldrich, Cotia, Brazil), and chloroform (99.8\%, SigmaAldrich, Cotia, Brazil) were received and used in this work without further purification.

\section{Synthesis}

GSO was modified by two independent procedures: epoxidation and maleinization reactions. Then, both products were characterized and their properties compared.

\section{Epoxidized grape seed oil (EGSO)}

The synthesis was adapted from literature, ${ }^{20}$ aiming to provide a greener method and higher yield value. The molar proportion of $\mathrm{C}=\mathrm{C}: \mathrm{H}_{2} \mathrm{O}_{2}$ :AA was equal to $1: 6: 1$. Firstly, GSO $(50 \mathrm{~g})$, AA $(14 \mathrm{~mL})$, the heterogeneous catalyst Amberlite-IR120 (25 g), and a magnetic bar were transferred into a round bottomed flask and then submitted to the heating. When the system reached $60^{\circ} \mathrm{C}$ (considered the zero time, $\left.\mathrm{t}_{0}\right), \mathrm{H}_{2} \mathrm{O}_{2}(43 \mathrm{~mL}$ ) was added in a single step, and the reaction was kept under stirring and reflux for $3 \mathrm{~h}$ (following the extent of reaction each hour); the resulting temperature profile throughout the synthesis can be seen in Figure S1a (Supplementary Information (SI) section). After $3 \mathrm{~h}$, the mixture was cooled, filtered to recover the catalyst and then transferred into a separatory funnel. It was added ethyl acetate $(50 \mathrm{~mL})$, to facilitate the aqueous phase separation. Thereafter, the aqueous phase was discarded, and the organic one was washed with an aqueous solution of $\mathrm{Na}_{2} \mathrm{CO}_{3}\left(0.1 \mathrm{~mol} \mathrm{~L}^{-1}\right)$ until reaches the neutral $\mathrm{pH}$. Then, the system was transferred into an Erlenmeyer flask and anhydrous $\mathrm{MgSO}_{4}$ was added to remove remaining water and then it was finally filtered using a vacuum pump and the ethyl acetate was evaporated in a rotary evaporator. At the end of purification process, a colorless liquid was obtained. The values of conversion, yield, and selectivity were calculated following the literature. ${ }^{22}$

\section{Maleinized grape seed oil (MGSO)}

The maleinization of vegetable oil using microwave irradiation was optimized by the research group and it is described in a previous paper. ${ }^{31}$ To summarize, GSO (30 g) 
and MA (15 g) were added into a Teflon ${ }^{\circledR}$ reactor and then submitted to microwave heating $\left(10^{\circ} \mathrm{C} \mathrm{min}^{-1}\right)$ and kept at $235^{\circ} \mathrm{C}$ for $15 \mathrm{~min}$.

The experimental temperature control can be seen in Figure S1b (SI section). The synthesis resulted in a viscous liquid (dark orange) product.

\section{Characterization}

Titrations: iodine value (IV), epoxy content, and anhydride quantification in modified oil structure

All iodine values and epoxy content were calculated following the standards ASTM D554-15 $5^{34}$ and ASTM D1652-11, ${ }^{35}$ respectively. The quantity of maleic anhydride incorporated onto the GSO structure was calculated following the procedure previously described. ${ }^{31}$ All titrations were performed in triplicate.

Mid-infrared spectroscopy (MIR), nuclear magnetic resonance $\left({ }^{1} \mathrm{H}\right.$ and $\left.{ }^{13} \mathrm{C} \mathrm{NMR}\right)$, and ultraviolet and visible light spectroscopy (UV-Vis)

The spectra in the mid-infrared region obtained using a Vertex 70 spectrometer (Bruker, Berlin, Germany) using the same conditions described in a previous work. ${ }^{31}{ }^{1} \mathrm{H}$ and ${ }^{13} \mathrm{C}$ NMR analyses were performed using chloroform $\left(\mathrm{CDCl}_{3}, 99.8 \% \mathrm{D}\right.$, Sigma-Aldrich, Cotia, Brazil) as solvent in an Ascend III $600 \mathrm{MHz}$ spectrometer (Bruker, Berlin, Germany). Following the literature, ${ }^{36}$ it was determined that polyunsaturated fatty acid chains are the main acids present in GSO with $62.9 \%$, followed by monounsaturated fatty acid with $23.3 \%$, and the saturated represents $13.8 \%$. These results are close to those found in literature. ${ }^{8}$ In addition, the double bond average $\left(\mathrm{GSO} \mathrm{DB}_{\text {average }}=4.3\right)$, and the iodine value $\left(\mathrm{GSO} \mathrm{IV}_{\mathrm{NMR}}=122.97\right)$ were calculated by ${ }^{1} \mathrm{H}$ NMR. ${ }^{37}$ The parameters used for the obtention of UV-Vis spectra were the same that those previous described using a spectrophotometer model Cary 8854 (Agilent Technologies, Santa Clara, United States of America). ${ }^{31}$ A UV lamp (model PR160-370 nm, Kessil, Import now, São Carlos, Brazil) was used for the qualitative analysis.

\section{Thermal analysis}

Simultaneous thermogravimetry-differential thermal analysis (TG-DTA) were performed in a STA 499 F3 (Netzsch, Selb, Germany), while differential scanning calorimetry (DSC) curves were obtained in a DSC Star System (Mettler-Toledo, Columbus, United State of America). Excepted for sample mass (27 mg in TG-DTA and $8 \mathrm{mg}$ in DSC), all other experimental conditions used in TG-DTA and DSC analyses were the same that described in a previous work. ${ }^{31}$

\section{Density and viscosity measurements}

The density $(\rho)$ was determined using a pycnometer of $25 \mathrm{~mL}$ at $27^{\circ} \mathrm{C}$. The measurements were made in triplicate. All viscosity $(\eta)$ measurements were performed in a Brookfield DV-III rheometer (Brookfield, Toronto, Canada) which was connected to a water bath for temperature control. The measurements were performed at four temperatures: $27,40,60$, and $80{ }^{\circ} \mathrm{C}$. Due to the different viscosities observed for each sample and considering the specific interval of viscosity for each spindle, each sample used a different spindle: SC4-18 for GSO, SC4-34 for EGSO, and for the MGSO two spindles were used: LV4-63 (at $27^{\circ} \mathrm{C}$ ) and SC4-34 for the other temperatures (40, 60, and $80{ }^{\circ} \mathrm{C}$ ). The shear rate was varied between 10 and $100 \%$ of torque range, as recommended by the manufacture.

\section{Results and Discussion}

The GSO has a greenish color, as exhibited in Figure 1a. After the modifications, the product changed color, as can be seen in Figures $1 \mathrm{~b}$ and 1c. The epoxidation provided an almost colorless product (EGSO); while the maleinization resulted in a dark orange product (MGSO).

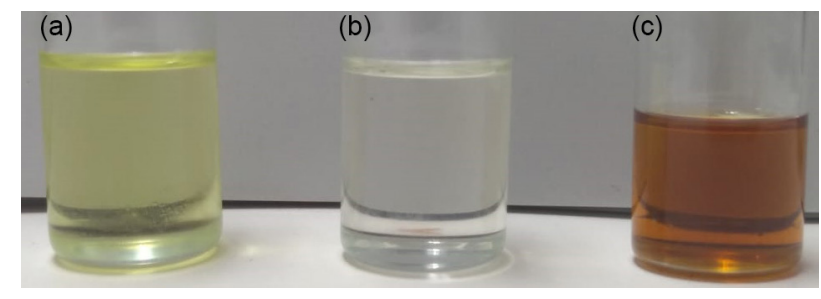

Figure 1. (a) Grape seed oil (GSO), and the products from its modification (b) epoxidized grapeseed oil (EGSO), and (c) maleinized grapeseed oil (MGSO).

Titration methods were used to determine the IV values for the GSO (121.58 \pm 0.86$)$. This indicated that each $100 \mathrm{~g}$ of oil contained $478.98 \mathrm{mmol}$ of double bonds, value similar to the soybean oil. ${ }^{31}$ Hence, the GSO used in this work can be considered as a semi-drying oil, which is the most used in monomer and polymer field. ${ }^{5}$ The IV values obtained for EGSO and MGSO were 0.78 \pm 0.25 , and 62.54 \pm 0.79 , respectively. The modifications provided $4.74 \pm 0.10 \mathrm{mmol}$ of epoxy in the EGSO, and $179.00 \pm 0.08 \mathrm{mmol}$ of anhydride per gram in MGSO. Furthermore, the density $(\rho)$ for GSO at $27{ }^{\circ} \mathrm{C}$ was equal to $923.2 \pm 5.0 \mathrm{~kg} \mathrm{~m}^{-3}$, which increased after epoxidation to $996.20 \pm 2.0 \mathrm{~kg} \mathrm{~m}^{-3}$ and to $1019.90 \pm 1.0 \mathrm{~kg} \mathrm{~m}^{-3}$ after maleinization. The increased density was due to the different groups incorporated onto the GSO, the epoxy rings provide a higher chain packing (due to the new fatty chain conformation), resulting even in sample solidification at room temperature for some 
ones, such as the epoxidized baru oil. ${ }^{37}$ On another hand, the maleinization reaction provides the incorporation of more electronegative groups; increasing the intermolecular interaction and therefore the density of sample. Similar result has been observed for Cai et al. ${ }^{38}$ when they epoxidized and then carbonated cottonseed oil.

MIR

The resulting spectra for GSO, EGSO, and MGSO are illustrated in Figure 2. As expected, the GSO spectrum (Figure 2a) is very similar to those observed for other vegetable oils ${ }^{31,37}$ thus, the main bands (those involved in or affected by the modification reactions) are an intense band at $1743 \mathrm{~cm}^{-1}$ associated to $\mathrm{C}=\mathrm{O}$ stretching of carbonyl ester and other three bands at 2854, 2923, and $3008 \mathrm{~cm}^{-1}$ related to the stretching of $\mathrm{C}-\mathrm{H}$ groups. The last one refers to the stretching of vinyl hydrogen from $\mathrm{C}=\mathrm{C}-\mathrm{H} .{ }^{39}$ Lastly, the band at $1654 \mathrm{~cm}^{-1}$ (pointed by an arrow) refers to the $\mathrm{C}=\mathrm{C}$. After epoxidation reaction, the triglyceride structure remained almost the same; however, three changes can be observed in its spectrum (Figure 2b). First, the band at $1654 \mathrm{~cm}^{-1}$ vanished due to $\mathrm{C}=\mathrm{C}$ consumption in epoxidation reaction, as a consequence, the band related to the stretching of vinylic hydrogen $\left(3106 \mathrm{~cm}^{-1}\right)$ also disappeared. The epoxy ring (a three membered ring) should have provided three bands between 1280 and $1230 \mathrm{~cm}^{-1}$ (ring stretching). The two other bands in the range of $950-815$ and $880-750 \mathrm{~cm}^{-1}$ were due to symmetric and asymmetric ring deformation, respectively. However, due to the similarity between EGSO and GSO spectra, only those bands attributed to the ring deformation at 842 and $823 \mathrm{~cm}^{-1}$ are observed. The absence of a large band between 3500 and $3200 \mathrm{~cm}^{-1}$ indicates that parallel reactions did not occur throughout the epoxidation reaction, such as hydroxyl groups formation due to epoxy ring-opening process. ${ }^{26,40}$ Based on these changes, the $\mathrm{C}=\mathrm{C}$ bonds yield into epoxy rings were evaluated; the resulting MIR spectra can be seen in Figure S2 (SI section). It is clear that after $4 \mathrm{~h}$ the product cannot be considered just an epoxidized product; instead, it is a by-product obtained by the partial consumption of epoxide rings. Hence, the optimal reaction time was set as $3 \mathrm{~h}$. These results support the temperature profile throughout the synthesis (Figure S1a).

The epoxidation of GSO has been described in literature using different conditions (Table 1); ${ }^{18,22-25}$ however, neither of them reached conversion, yield, and selectivity values similar to those reported in this paper. They demanded more energy, or more time, or pressure increasing. In addition, a monomer production with high values of epoxide (related to conversion and yield values), and with low or without hydroxyl groups produced by parallel reaction (associated with selectivity value), is important to its further application. The presence of residual double bonds or hydroxyl groups would interfere in the crosslink reaction and therefore in the final polymer properties.

Although the reuse of Amberlite-IR 120 in epoxidation reaction has been reported in literature for the epoxidation of vegetable oils, the conditions in synthesis were different between a reaction and another. In addition, the catalyst had been filtrated and washed with different solvents, such as ethanol and deionized water; ${ }^{40}$ or only with water followed by a dry process, ${ }^{41}$ or diethyl ether followed by drying. ${ }^{42-44}$ Therefore, aiming to evaluate the catalyst in industry with less residue generation with less steps in the process and also to complement the results in literature,

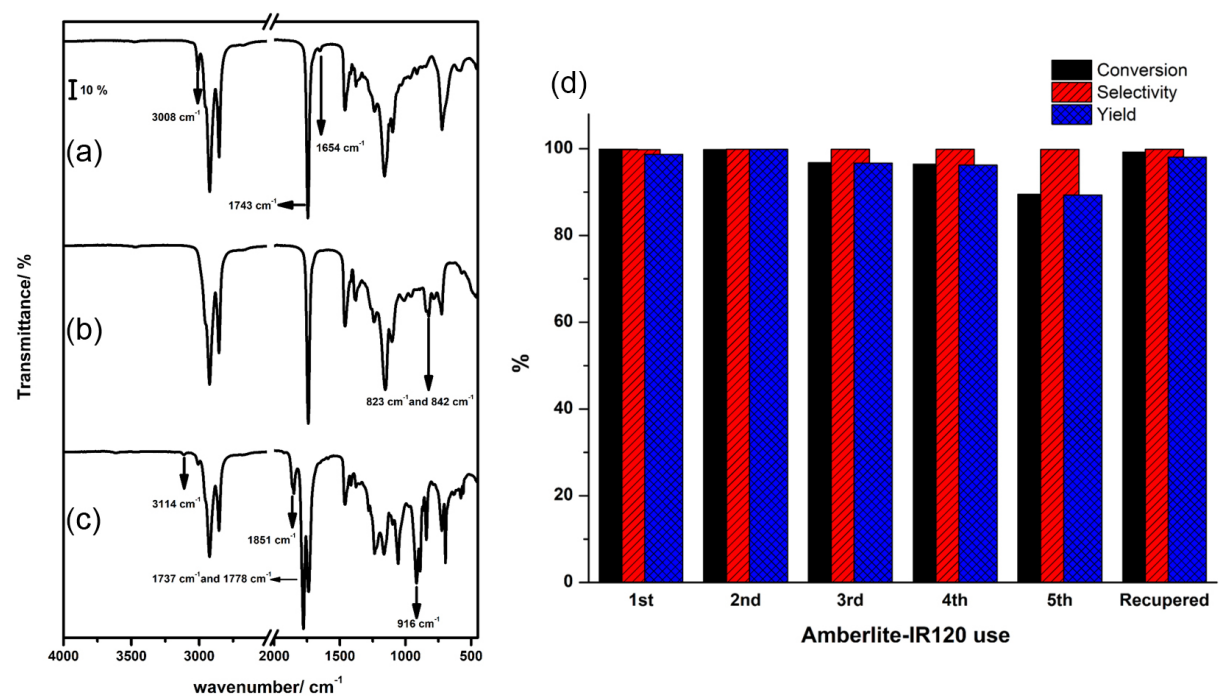

Figure 2. MIR spectra (ATR) of (a) GSO, and resulted monomers from its modification (b) EGSO, (c) MGSO, and (d) data obtained for the reusability of Amberlite-IR120. 
Table 1. Experimental conditions set and conversion, yield and selectivity values achieved in this work compared to other epoxidation synthesis reported in literature

\begin{tabular}{|c|c|c|c|c|c|c|}
\hline & This work & Reference 18 & Reference 22 & Reference 23 & Reference 24 & Reference $25^{\mathrm{b}}$ \\
\hline Conversion / \% & 99.4 & not complete ${ }^{\mathrm{a}}$ & ca. $45 \%$ c & $-\mathrm{b}$ & $-{ }^{\mathrm{b}}$ & $93.5^{\mathrm{g}}$ \\
\hline Yield / \% & 98.9 & $-{ }^{\mathrm{b}}$ & 8.31 & 86 & 85 & $74.2^{\mathrm{g}}$ \\
\hline Selectivity / \% & 99.5 & $-^{\mathrm{b}}$ & ca. $20 \%$ c & $--^{b}$ & $-^{\mathrm{b}}$ & $79.4^{\mathrm{g}}$ \\
\hline $\mathrm{n}_{\mathrm{C}=\mathrm{C}}: \mathrm{n}_{\mathrm{H} 2 \mathrm{O} 2}: \mathrm{n}_{\mathrm{AA}}$ & $1: 6: 1$ & $1: 1.5: 0.5$ & $1: 6: 0.3^{\mathrm{d}}$ & $1: 8: 0.5$ & $1: 10: 0.5$ & $1: 2: 0.5$ \\
\hline Temperature $/{ }^{\circ} \mathrm{C}$ & 60 & 55 & 40 & 80 & $55 / 65$ & 90 \\
\hline time / h & 3 & 24 & 15 & overnight & $5 / 1$ & 1 \\
\hline Pressure / atm & 1 & 1 & 148 & 1 & 1 & 1 \\
\hline Catalyst & $\begin{array}{c}\text { heterogeneous/ } \\
\text { Amberlite }{ }^{\circledR} \text { IR120 }\end{array}$ & $\begin{array}{c}\text { heterogeneous/ } \\
\text { Amberlite }{ }^{\circledR} \text { IR } 120\end{array}$ & $\begin{array}{c}\text { heterogeneous/ } \\
\text { HDTMAB }^{\mathrm{e}}\end{array}$ & $\begin{array}{c}\text { heterogeneous/ } \\
\text { Amberlite }{ }^{\circledR} \text { IR } 120\end{array}$ & $\begin{array}{c}\text { homogeneous/ } \\
\mathrm{H}_{2} \mathrm{SO}_{4}\end{array}$ & $\begin{array}{c}\text { homogeneous/ } \\
\mathrm{H}_{2} \mathrm{SO}_{4}\end{array}$ \\
\hline Solvent & no & yes/toluene & yes $/ \mathrm{CO}_{2}{ }^{\mathrm{f}}$ & no & no & no \\
\hline Heating type & conventional & conventional & conventional & conventional & conventional & conventional \\
\hline
\end{tabular}

at was not demonstrated the exact value, however by MIR spectra it was possible to observe residual $\mathrm{C}=\mathrm{C}$ bonds; bit was not described in the paper and it was not possible to calculated it with the provided data; ${ }^{\mathrm{c}}$ obtained in a graph, the authors did not write the exact value; ${ }^{\mathrm{d}} \mathrm{molar}$ proportion between $\mathrm{n}_{\mathrm{C}=\mathrm{C}}$ :

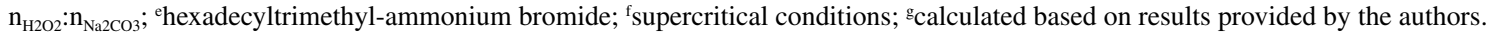

Amberlite-IR120 was reused without any treatment. After each reaction, it was just filtrated and when considerable decreased of conversion was achieved, it was submerged in concentrated hydrochloric acid and stirred for $30 \mathrm{~min}$, and then washed with distilled water. The results for conversion, selectivity, and yield obtained for each reaction are shown in Figure $2 d$. Until the $4^{\text {th }}$ time none considerable change was observed; however, in the $5^{\text {th }}$ Amberlite-IR120 use, conversion and yield values decreased to 89.5 and $89.3 \%$, respectively. Although this changing, it is observed that the selectivity of reaction kept high (>99.0\%). After the catalyst recuperation, it is observed that three values returned to values higher than $99.0 \%$. Hence, these results complement those reported in literature ${ }^{40-44}$ and the Amberlite-IR120 presents a great potential to be used in industry as catalyst for epoxidation reaction. In addition, it is known that increasing the reactants the chemical equilibrium is displaced to the products formation (Le Châtelier's Principle), ${ }^{45}$ therefore, increasing $\mathrm{H}_{2} \mathrm{O}_{2}$ and AA amounts, in the presence of an efficient catalyst, the peracetic acid formation (slow step) is favored and then the quantity of products obtained (epoxidized fatty chains) is higher. However, it is important to control the reaction time to avoid parallel reactions that decrease the yield value.

The maleinization process provides different changes in GSO structure. The spectrum of MGSO is shown in Figure 2c, while Scheme 1 indicates the possible incorporation types of anhydrides onto vegetable oil structure. As expected, the MIR spectrum is very similar to that obtained for maleinized soybean oil using microwave irradiation. ${ }^{31}$ The bands associated to $\mathrm{C}=\mathrm{O}$ stretching of vegetable oil appears at $1778 \mathrm{~cm}^{-1}$, and due to the overlapping of anhydride carbonyls at $1737 \mathrm{~cm}^{-1}$ the carbonyl band is larger than observed for GSO and EGSO. Although most of literature reports the band at $1851 \mathrm{~cm}^{-1}$ to the asymmetric stretching of carbonyl in anhydride, this band can be an overtone of the intense band at $916 \mathrm{~cm}^{-1}$. This band is associated to the fivemember structure incorporated on vegetable oil as succinic anhydride by the "ene" reaction or by radical addition (reactions I and II, respectively in Scheme 1). ${ }^{20,46}$ The band at $3008 \mathrm{~cm}^{-1}$ indicates that the vegetable oil structure contains vinylic hydrogens, which could be associated to the product obtained in both these reactions. However, as can be seen in Scheme 1, other possible types of anhydrides can be incorporated onto vegetable oil: radical addition by deprotonation (reaction III), Diels-Alder addition that can occur after isomerization by heating or light (reaction IV), and crosslinking (reaction V). ${ }^{27,46}$ Furthermore, the small band at $3114 \mathrm{~cm}^{-1}$ in MGSO did not appear in the GSO or EGSO spectra, suggesting the presence of other vinyl hydrogens in the structure. This region is magnified in Figure S3 (SI section) together with the maleic anhydride spectrum. However, based only on MIR results, it is difficult to identify the incorporation types of anhydrides onto GSO structure; hence, NMR analysis is necessary.

\section{UV-Vis}

A qualitative test was performed by placing samples under a UV-light, the result can be seen in Figure S4 (SI section). The GSO exhibits a strongly luminescent property, and after the epoxidation this property was lost, while after maleinization reaction, the luminesce changed. The detailed discussion about the changes in spectra are shown in SI section. 
(I)

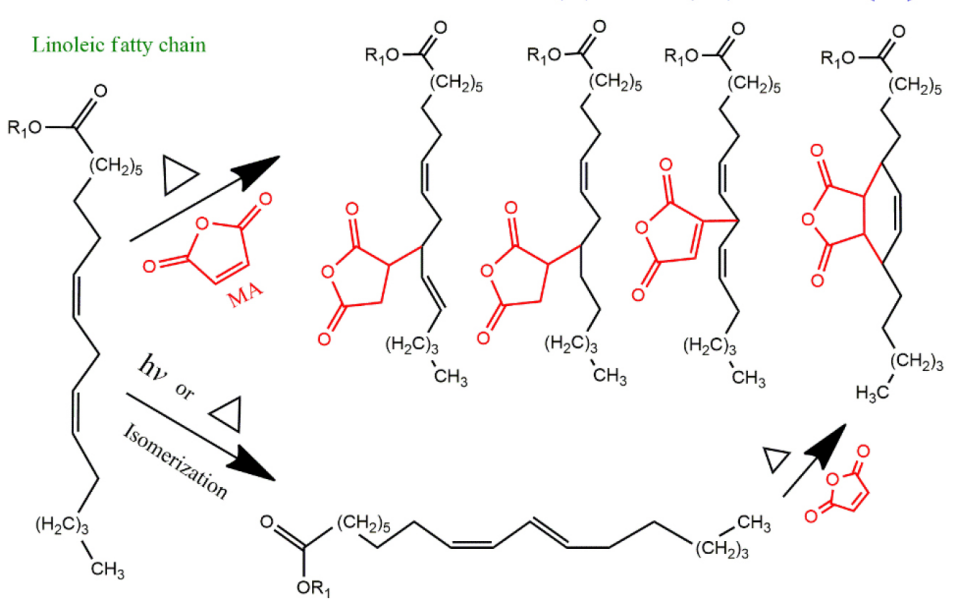

(IV)

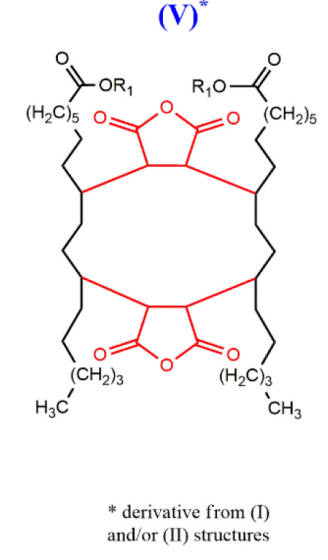

Scheme 1. Possible incorporation types of maleic anhydride onto vegetable oil chain (here represented as linoleic acid): (I) "ene" reaction; (II) radical addition; (III) radical addition by deprotonation; (IV) Diels-Alder addition; and (IV) crosslinking.

${ }^{1} \mathrm{H}$ NMR

The ${ }^{1} \mathrm{H}$ NMR spectrum for GSO, as well as the main signals are shown in SI section (Figure S6). By its spectrum was possible to obtain the DB average and IV values following the literature which are summarized in Table 2. ${ }^{36,37}$

The signal at $2.04 \mathrm{ppm}$ refers to the hydrogens from the methylene group vicinal of the double bonds in all unsaturated fatty acids. This signal vanished after epoxidation reaction, as can be seen in the EGSO spectrum (Figure 3a). The absence of this signal and another at $2.77 \mathrm{ppm}$ (related to the hydrogens of methylene groups between two alkenes) suggest that double bonds do not remain in EGSO structure. This is confirmed by the absence of the signal at $5.35 \mathrm{ppm}$, which refers to the vinyl hydrogen $[-\mathrm{CH}=\mathrm{CH}-]$. As a result, new signals are observed at 1.49 and $1.72 \mathrm{ppm}$, which are related to the hydrogens from methylene groups on the monounsaturated and polyunsaturated chains, respectively. The resulting signals from hydrogen epoxides are observed in 2.90, 2.98, 3.07, and $3.11 \mathrm{ppm}$. These results are in agreement with the signals observed in other epoxidized oils. ${ }^{37,47}$ These results and the IV values obtained after epoxidation reaction (Table 2) support the MIR results. The GSO epoxidation performed using heterogeneous catalyst for $3 \mathrm{~h}$ provided a yield close to $99.0 \%$. It can be seen that most of syntheses described in literature (Table 1) use higher temperatures with more time demanding, and homogeneous catalysts using, which requires more washing processes in purification step and goes against the Principles related to avoid wastes in Green Chemistry ( $1^{\text {st }}$ Principle) and Green Engineering ( $2^{\text {nd }}$ Principle). Therefore, the epoxidation synthesis reported in this work can be considered a more efficient, cleaner, and a less energetic process than other syntheses reported in literature..$^{20,21,25}$

As expected, the changes in ${ }^{1} \mathrm{H}$ NMR spectrum for MGSO (Figure 3b) refer just to the hydrogens from anhydride incorporation; all the other signals observed in GSO spectrum were kept. The absence of a singlet at $7.10 \mathrm{ppm}$ confirms there was no residual maleic anhydride in the MGSO. As aforementioned, there are five ways to incorporate anhydride onto vegetable oil structure (Scheme 1). Considering the experimental conditions used in this work, and the data reported in the literature, the ${ }^{1} \mathrm{H}$ and ${ }^{13} \mathrm{C}$ NMR results (details discussed in SI section, Figures S7 and S8) associated to the other techniques indicate the occurrence of four different ways of anhydride incorporation into GSO are suggested: "ene" reaction, radical addition, radical addition by deprotonation, and

Table 2. Iodine value (IV), average number of alkene double bonds $\left(\mathrm{DB}_{\text {average }}\right)$, and epoxy content for the samples

\begin{tabular}{lcccc}
\hline & Method & GSO & EGSO & MGSO \\
\hline $\mathrm{IV} /\left(\mathrm{g} \mathrm{I}_{2}\right.$ per $100 \mathrm{~g}$ of sample $)$ & ${ }^{1} \mathrm{H}$ NMR & 122.97 & 0 & 69.31 \\
\hline $\mathrm{DB}_{\text {average }}$ per triglyceride molecule & titration & $121.58 \pm 0.86$ & $0.78 \pm 0.25$ & $62.54 \pm 0.79$ \\
\hline
\end{tabular}

GSO: grape seed oil; EGSO: epoxidized grape seed oil; MGSO: maleinized grape seed oil; IV: iodine value; $\mathrm{DB}_{\text {average }}$ double bond average; NMR: nuclear magnetic resonance. 
(a)
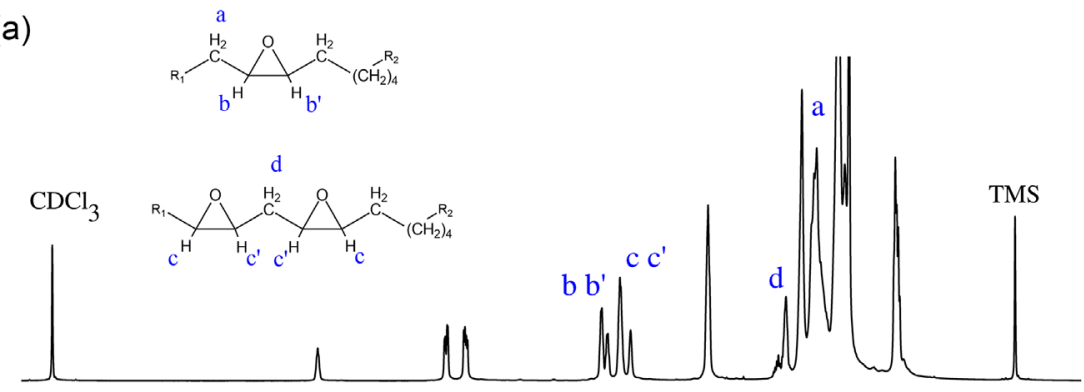

(b)

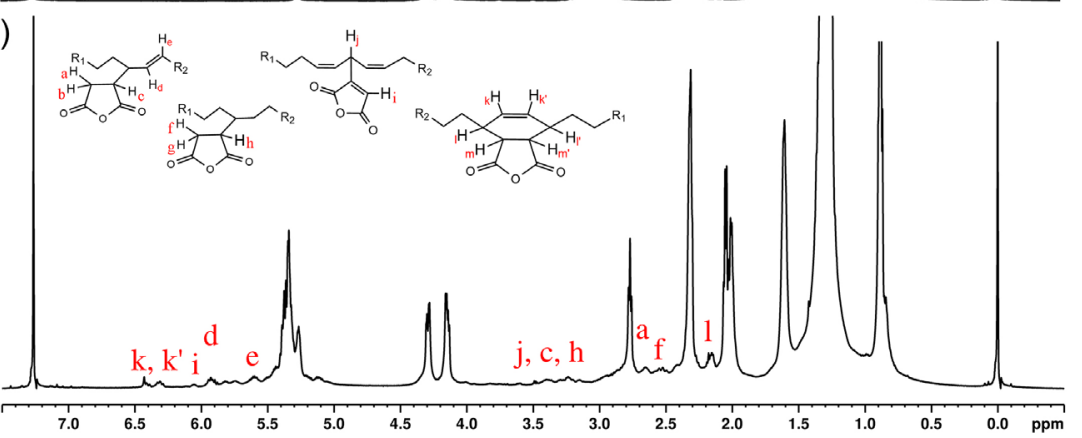

Figure 3. ${ }^{1} \mathrm{H}$ NMR spectra ( $600 \mathrm{MHz}, \mathrm{CDCl}_{3}$ ) for (a) EGSO and (b) MGSO.

Diels-Alder addition (reactions I, II, III, and IV, respectively in Scheme 1).

These results indicate that the maleic anhydride was efficiently incorporated onto GSO structure, which were supported by MIR, UV-Vis, and NMR results as well as the physical changes (coloration, $\rho$, and $\eta$ ). However, it is not possible to determine the extent of each reaction using neither NMR results (due to the overlapping of some signals) nor by titration (because each reaction provides different changes on IV values).

\section{TG-DTA}

TG/DTG-DTA curves of GSO, EGSO, and MGSO are shown in Figure 4. The thermal stability of GSO $\left(290.5^{\circ} \mathrm{C}\right)$ is higher than most of vegetable oils, such as soybean oil (around $\left.270{ }^{\circ} \mathrm{C}\right),{ }^{31}$ babassu $\left(250.0^{\circ} \mathrm{C}\right.$ ), andiroba $\left(235.0{ }^{\circ} \mathrm{C}\right),{ }^{48}$ macaw $\left(217.3{ }^{\circ} \mathrm{C}\right)$, and baru $\left(260.8{ }^{\circ} \mathrm{C}\right)$ oils. ${ }^{37}$ Heating can provide the formation of peroxides and hydroperoxides, due to the addition of oxygen gas in carbons between two alkenes (presents in linoleic and $\omega$-linolenic acids); thereafter, these peroxides can attack double bonds by radical process resulting in an oxidation process and consequently mass loss in TG curve. ${ }^{8}$ As consequence, the thermal stability usually decreases with the increasing of unsaturated fatty acids in the vegetable oil. ${ }^{48,49}$ However, in this work, even with $86.2 \%$ of unsaturated fatty acids, the GSO has a higher thermal stability, which is may attributed to the presence of natural antioxidants, such as phenolic compounds. ${ }^{49}$ Except for the thermal stability, the thermal behavior of GSO is very similar to other vegetable oils, ${ }^{31,37}$ the first mass loss occurred between 290.5 and $482.5^{\circ} \mathrm{C}$ $(\Delta \mathrm{m}=94.82 \%)$, and it resulted from two complexes and overlapping/consecutive events as exhibited in DTG curve. Each one with values of maximum degradation rate (MDR) equal to $2.973 \mathrm{mg} \mathrm{min}^{-1}$ and temperature of maximum degradation rate $\left(\mathrm{T}_{\mathrm{pMDR}}\right)$ equal to $386.0^{\circ} \mathrm{C}$ and $2.278 \mathrm{mg} \mathrm{min}^{-1}\left(\mathrm{~T}_{\mathrm{pMDR}}=415.6{ }^{\circ} \mathrm{C}\right)$, respectively. This step may be related to the thermal decomposition of unsaturated fatty chains (poly and monounsaturated). ${ }^{46}$ The second step of mass loss occurred in the range from 482.5 to $597.5{ }^{\circ} \mathrm{C}(\Delta \mathrm{m}=5.14 \%)$ and can be associated to the decomposition of saturated chains and oxidation of the remaining unsaturated chains. ${ }^{48}$ Furthermore, this step was slower than the first one, as evidenced by MDR value: $0.186 \mathrm{mg} \mathrm{min}^{-1}\left(\mathrm{~T}_{\mathrm{pMDR}}=541.8^{\circ} \mathrm{C}\right)$. As expected, both steps of mass loss result in exothermic peaks in DTA curve at $389.4^{\circ} \mathrm{C}$ and $529.8^{\circ} \mathrm{C}$, respectively.

The TG/DTG-DTA curves of EGSO are exhibited in Figure 4b. The thermal decomposition profile was very similar to GSO: two steps of mass loss (the first one resulting from at least two overlapped and consecutives events) associated to exothermic peaks in DTA curve. However, its thermal stability $\left(219.0^{\circ} \mathrm{C}\right)$ decreased around $70.0^{\circ} \mathrm{C}$ compared to the GSO. The first mass loss occurred between 219.0 and $480.4{ }^{\circ} \mathrm{C}(\Delta \mathrm{m}=90.92 \%)$ and may be attributed to the epoxy ring degradations followed by the fatty chain degradation. This was clarified based on changes on the exothermic peaks in DTA curve, in which GSO had just one, while EGSO displayed two exothermic peaks at 376.2 and $419.0{ }^{\circ} \mathrm{C}$. In addition, the first value of MDR associated to the first mass loss also changed, while the 


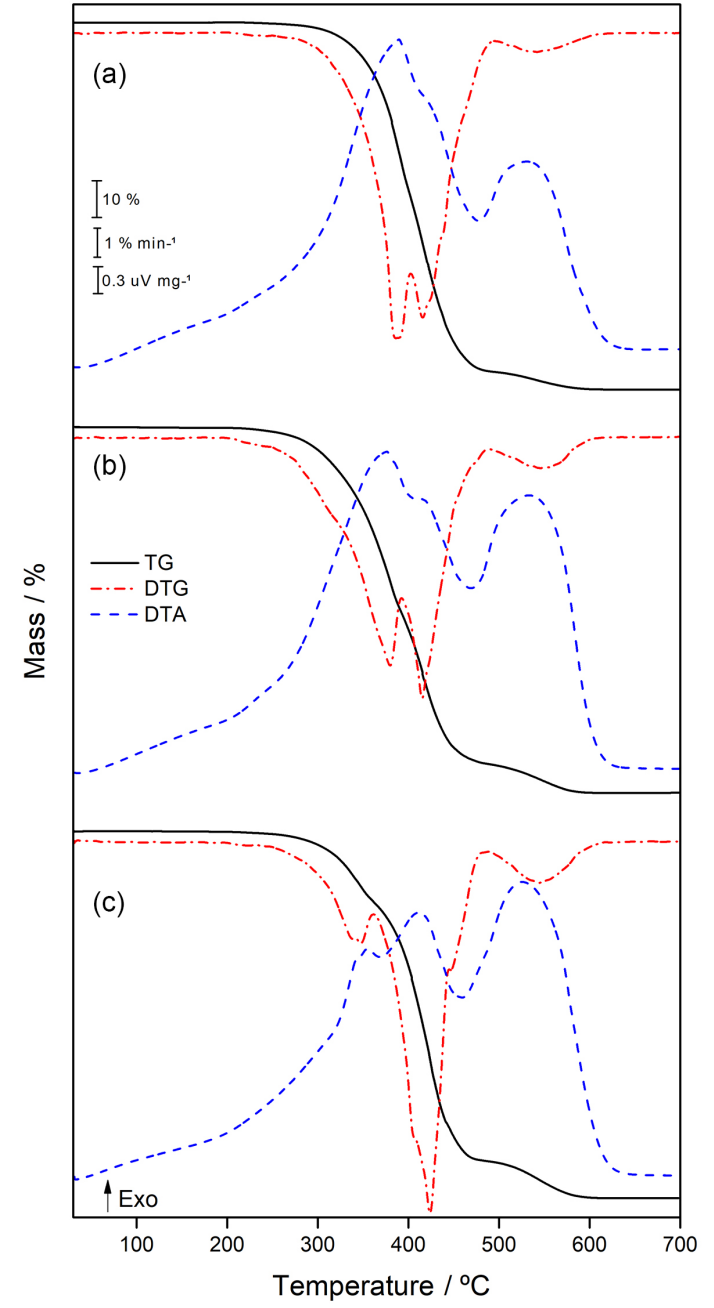

Figure 4. TG/DTG-DTA curves for (a) GSO, (b) EGSO, and (c) MGSO.

second did not change: $2.134 \mathrm{mg} \mathrm{min}^{-1}\left(\mathrm{~T}_{\mathrm{pMDR}}=379.8^{\circ} \mathrm{C}\right)$ and $2.442 \mathrm{mg} \mathrm{min}^{-1}\left(\mathrm{~T}_{\mathrm{pMDR}}=415.1^{\circ} \mathrm{C}\right)$. As expected, the second step of mass loss occurred without significant difference when compared to GSO, from $480.4{ }^{\circ} \mathrm{C}$ to $590.4^{\circ} \mathrm{C}(\Delta \mathrm{m}=8.01 \%)$ simultaneously with an exothermic peak in the DTA curve at $533.2{ }^{\circ} \mathrm{C}$, and MDR equal to $0.286 \mathrm{mg} \mathrm{min}^{-1}$ at $\mathrm{T}_{\mathrm{pMDR}}=545.7^{\circ} \mathrm{C}$.

Finally, the TG/DTG curves of MGSO (Figure 4c) show that the sample was stable up to $263.1{ }^{\circ} \mathrm{C}$; which has a temperature of thermal stability between GSO and EGSO (similar to previous work). ${ }^{31}$ It also decomposed in two steps of mass loss, in which the first one occurred between 263.1 and $474.1{ }^{\circ} \mathrm{C}(\Delta \mathrm{m}=89.10 \%)$ and, as expected, it was a complex decomposition (overlapped steps). The DTG curve indicates three overlapped steps, at least; the first one can be attributed to degradation of incorporated anhydride on GSO structure, while the other could be the decomposition of the modified chains. These events result in two exothermic peaks in DTA curve (355.2 and $411.9^{\circ} \mathrm{C}$ ) and in two well-defined events in the DTG curve, resulting in MDR values equals to $0.965 \mathrm{mg} \mathrm{min}^{-1}$ $\left(\mathrm{T}_{\mathrm{pMDR}}=343.7^{\circ} \mathrm{C}\right)$ and $3.662 \mathrm{mg} \mathrm{min}^{-1}\left(\mathrm{~T}_{\mathrm{pMDR}}=423.9^{\circ} \mathrm{C}\right)$. The second step of mass loss occurred between 471.1 and $593.3{ }^{\circ} \mathrm{C}\left(\Delta \mathrm{m}=10.27 \%\right.$; MDR $=0.404 \mathrm{mg} \mathrm{min}^{-1}$; $\mathrm{T}_{\mathrm{pMDR}}=544.2^{\circ} \mathrm{C}$ ) and resulted in an exothermic peak in DTA curve at $525.6^{\circ} \mathrm{C}$.

By TG/DTG-DTA curves an order of thermal stability was determined: EGSO $<$ MGSO $<$ GSO. Moreover, one more exothermic peak in DTA curve can be observed for modified vegetable oils and a significant decreasing in the first MDR value associated to the first mass loss (beginning of decomposition). These decreasing resulted from the interaction between the chains provided by the modification of double bonds from unsaturated fatty acids. Therefore, the MGSO decomposed slowly due to the types of anhydride incorporation (reactions I, II, and II in Scheme 1), which may increase the disorder in structures and provide a more viscous product, which will be discussed further.

DSC

The DSC curve of GSO, as well as the related discussion, are shown in SI section (Figure S9). As illustrated in Figure 5a, the EGSO displayed different thermal behavior. It was liquid at room temperature and slowly crystallized at $-32.8{ }^{\circ} \mathrm{C}$ (enthalpy $(\Delta \mathrm{H})=1.1 \mathrm{~J} \mathrm{~g}^{-1}$ ). This was supported by both endothermic peaks observed in the first heating, which were related to the melting process. The first one $\left(\mathrm{T}_{\mathrm{p}}=-15.4^{\circ} \mathrm{C}\right.$ and $\left.\Delta \mathrm{H}=5.9 \mathrm{~J} \mathrm{~g}^{-1}\right)$ is related to unsaturated chain, which is non-intersoluble into the epoxidized chains; therefore, they have less physical interaction between these fatty acid chains, while the second one $\left(\mathrm{T}_{\mathrm{p}}=-0.3{ }^{\circ} \mathrm{C}\right.$ and $\Delta \mathrm{H}=12.8 \mathrm{~J} \mathrm{~g}^{-1}$ ) refers to the melting of epoxidized chain, which demanded more energy to melt due to the higher structure packaging provided by the interactions between epoxy rings. ${ }^{37}$ In the second cooling in which the exothermic event associated with the crystallization $\left(\mathrm{T}_{\mathrm{p}}=-23.0^{\circ} \mathrm{C}\right.$ and $\left.\Delta \mathrm{H}=0.8 \mathrm{~J} \mathrm{~g}^{-1}\right)$, the displacement could be due to the better thermal homogenization of the sample (previously heated), and can be viewed better visualized in Figures S10c and S10d (SI section). A similar effect was observed for the melting of non-intersoluble chain $\left(\mathrm{T}_{\mathrm{p}}=-19.5^{\circ} \mathrm{C}\right.$ and $\left.\Delta \mathrm{H}=7.6 \mathrm{~J} \mathrm{~g}^{-1}\right)$; while for the second melting event no significant changes were observed $\left(\mathrm{T}_{\mathrm{p}}=-1.0^{\circ} \mathrm{C}\right.$ and $\left.\Delta \mathrm{H}=21.7 \mathrm{~J} \mathrm{~g}^{-1}\right)$.

The DSC curve for MGSO is presented in Figure $5 \mathrm{~b}$. Unlike for the GSO and EGSO, any exothermic event was observed in the first or second cooling. However, in both heating stages, a large endothermic event occurred, which was related to the melting of sample: $1^{\text {st }}$ heating: $\mathrm{T}_{\mathrm{p}}=-12.3{ }^{\circ} \mathrm{C}$ and $\Delta \mathrm{H}=3.5 \mathrm{~J} \mathrm{~g}^{-1}$ and $2^{\text {nd }}$ heating: $-11.3^{\circ} \mathrm{C}$ 

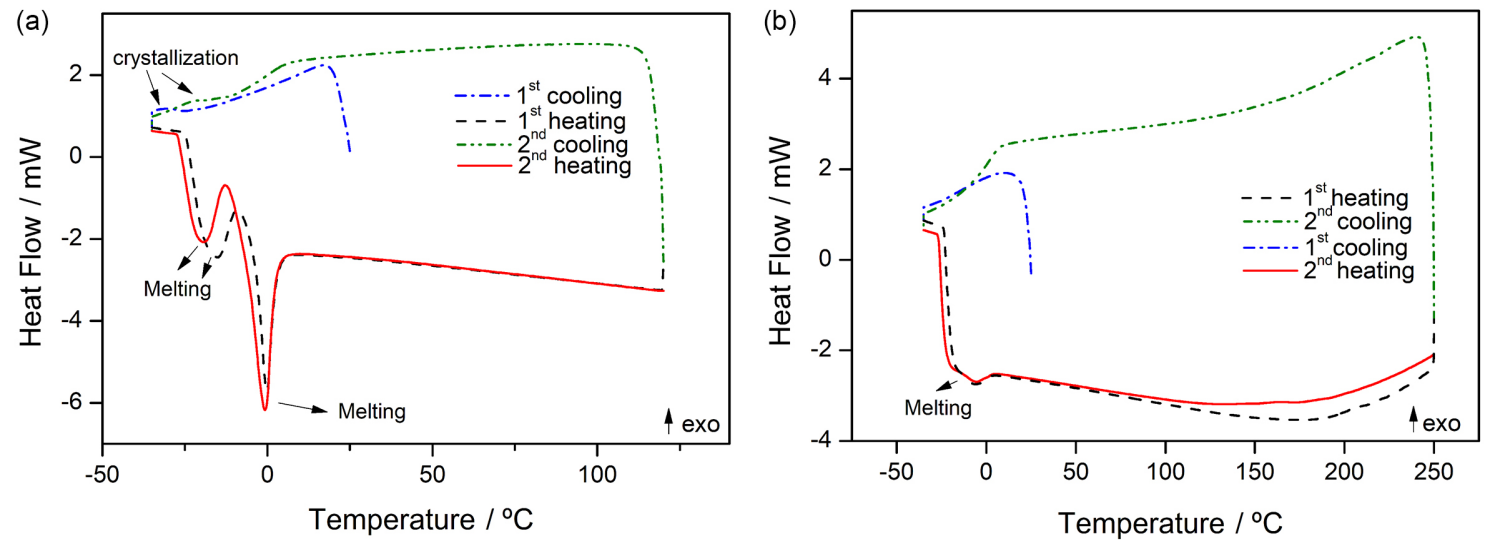

Figure 5. Cyclic DSC curves for (a) EGSO, and (b) MGSO.

and $\Delta \mathrm{H}=2.6 \mathrm{~J} \mathrm{~g}^{-1}$. The shoulder in both events indicated that each one resulted from at least two overlapping melting processes (unsaturated chains and with anhydrides incorporated chains). These phenomena may be associated with viscosity, which was higher than EGSO and GSO. Therefore, the crystallization process was so slow that it did not provide enough heat for the equipment detection. In addition, it is observed a baseline deviation in the first heating $180-230{ }^{\circ} \mathrm{C}$ (Figure S11, SI section), which repeats in the second heating $135-200{ }^{\circ} \mathrm{C}$. These events may be attributed to second order transitions that occur in MGSO structure, which become more aligned under heating (the decreasing of viscosity under heating will be better discussed in the next section). However, in DSC is not possible determine the exact temperatures values of these transitions, just the temperature intervals.

\section{Viscosity dependence on shear rate}

Independent of application, the rheological behavior will affect the performance of fluid. Therefore, this evaluation was essential to determine the possible fluid application, to design a process, or even as a quality control. Figure 6a exhibits the shear stress dependence on shear rate for GSO at $27{ }^{\circ} \mathrm{C}$, which has a linearity increasing; suggesting that the GSO behaved as a Newtonian fluid. ${ }^{50}$ Therefore, the viscosity would be constant independent of the velocity in which it was forced to flow. The slope of line using linear regression (Figure S12, SI section) elucidated its viscosity, following Newton's law: $46.02 \pm 2.8 \mathrm{mPa}$ s. The EGSO (Figure 6b) also exhibited a Newton behavior, and finding the slope of line (Figure S13, SI section), its viscosity at $27^{\circ} \mathrm{C}$ was $336.91 \pm 1.16 \mathrm{mPa}$ s. Unfortunately, for the MGSO, it was unable to measure the shear stress dependence on shear rate at $27{ }^{\circ} \mathrm{C}$ using the available spindles and respecting the limitations of each one. However, a single point at $50 \mathrm{rpm}$ at $27^{\circ} \mathrm{C}$ was measured, which resulted in a viscosity equal to $8792 \pm 20.19 \mathrm{mPa}$ s. The viscosities increasing after the epoxidation and maleinization were due to the different intermolecular interactions. For the EGSO, it is a result of intermolecular interaction between the epoxide rings (stronger than those from $\mathrm{C}=\mathrm{C}$ ), which can result in solid products at room temperature as observed in literature to baru oil. ${ }^{37}$ This was clarified by comparing the viscosity of epoxidized linseed oil (IV $=160$ and $87 \%$ of yield) at room temperature: $680 \mathrm{mPa} \mathrm{s} .{ }^{51}$ As a result, each modification in vegetable oil provides different viscosity values and behavior, for example after transesterification the viscosity of linseed oil decreased to $40 \mathrm{mPa} \mathrm{s}$, and after the oil acrylation, the viscosity was equal to $26.5 \mathrm{~Pa} \mathrm{~s}$ at $27{ }^{\circ} \mathrm{C}$, and the fluid behaved as a pseudoplastic (non-Newtonian). Similar behavior was observed comparing the soybean, cottonseed, and linseed oils after epoxidation and carbonatation. ${ }^{48}$

For the maleinized soybean oil the viscosity varied according to the amount of incorporated anhydride, ${ }^{31}$ and the optimal synthesis resulted in approximately $1.4 \mathrm{mmol}$ of anhydride per gram of modified oil (2983.0 mPa s). Here, the maleinization provided $1.79 \mathrm{mmol}$ of anhydride per gram of sample (16.2 g per $100 \mathrm{~g}$ of sample); as a result, the viscosity was higher at $27{ }^{\circ} \mathrm{C}(8792 \pm 20.19 \mathrm{mPa} \mathrm{s})$. The greater amount of anhydride increased the disorder of chains, and the alignment of chains was more difficult; as a result, the fluid offered higher resistance through the flow, justifying the increased viscosity: $20 \times$ and $190 \times$ higher than EGSO and GSO at $27^{\circ} \mathrm{C}$, respectively. Moreover, similar property was observed by Cai et al.,$^{50}$ after carbonatation all samples exhibited higher viscosity values than the epoxidized samples. However, even carbonated vegetable oils showed viscosity close to maleinized product (MGSO) obtained in this work at room temperature. This may be associated to the molecular mass of each group: carbonation provides the addition of 1 carbon and 3 oxygen on structure, while the maleinization results in 4 carbons and 3 oxygens. 

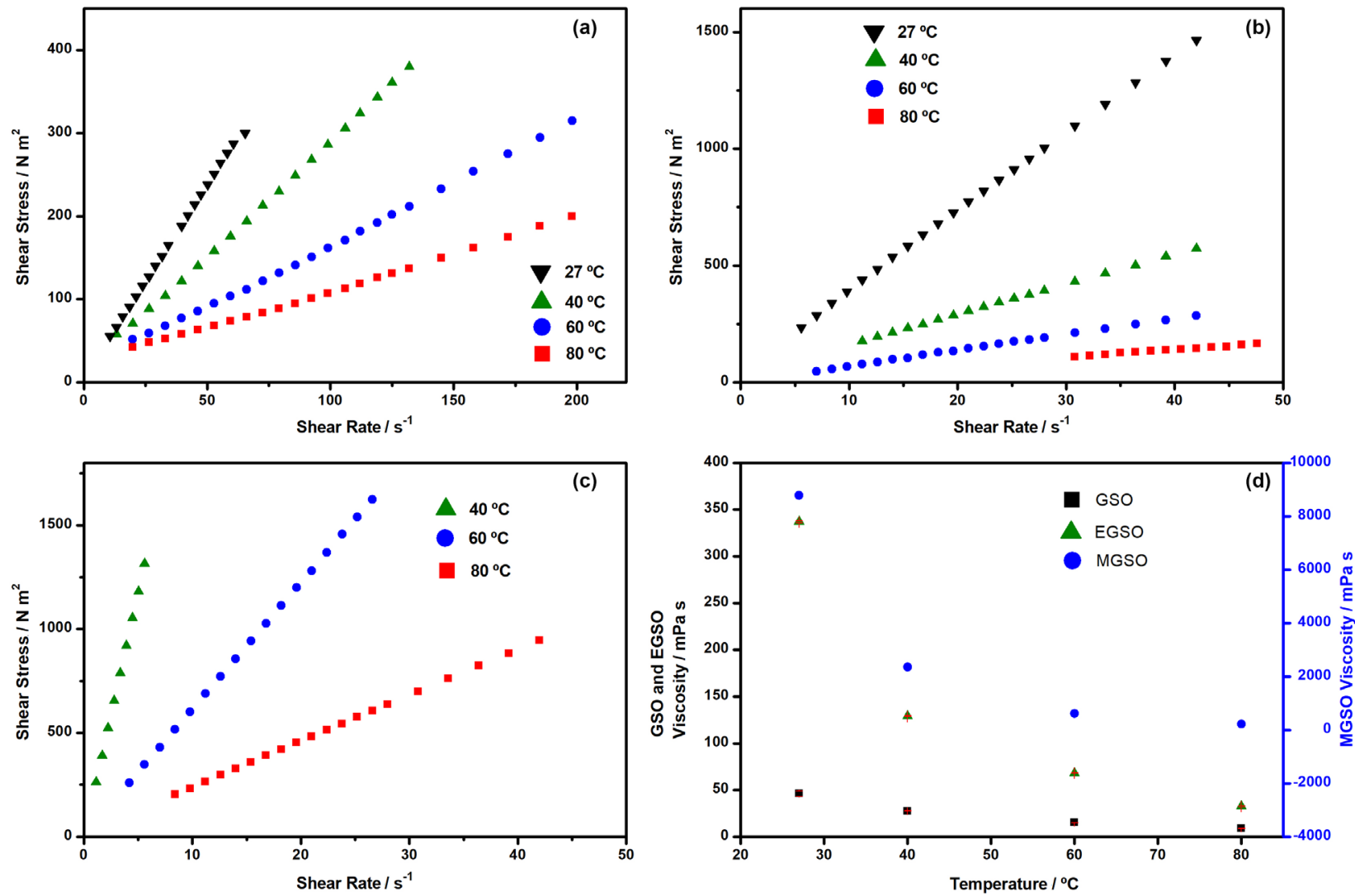

Figure 6. Shear stress $v s$. shear rate for (a) GSO, (b) EGSO, (c) MGSO at different temperatures, and (d) viscosity dependence on temperature for each sample.

As consequence, the structure disorder is higher, as well as the intermolecular interaction, resulting in greater viscosities values.

\section{Viscosity dependence on temperature}

The shear rate did not greatly affect the viscosity changes, which demonstrates that the internal structure was not broken. The shear rate can provide these changes; however, the temperature can result in more significant modification on viscosity. This occurs due to the energy absorb by the molecules, which reduces the intermolecular attraction forces. ${ }^{52}$ The temperature did not affect the flow behavior: all samples behaved as Newtonian fluid, as can be seen in Figures $6 \mathrm{a}, 6 \mathrm{~b}$, and $6 \mathrm{c}$. As performed before, the viscosities values for GSO, EGSO, and MGSO were determined using the Newton's law.
The resulted linear fit as well as the quality of each can be viewed in Figures S12, S13, and S14 (SI section). However, as observed in Figure 6d, all samples exhibited an exponentially decreased in viscosities values. Those obtained for GSO at 40,60 , and $80{ }^{\circ} \mathrm{C}$ (Table 3 ) were very similar to those obtained for oils with similar properties, such as soybean, safflower, and canola oils at the same temperatures. ${ }^{53}$

At $27^{\circ} \mathrm{C}$, the EGSO viscosity was $336.91 \pm 1.16 \mathrm{mPa}$ s, increasing the temperature to $40{ }^{\circ} \mathrm{C}$ the viscosity decreased more than $50 \%$ (Table 3), while at 60 and $80{ }^{\circ} \mathrm{C}$, the values were less than 30 and $10 \%$ comparing to the room temperature value. The MGSO exhibited viscosity values higher than GSO (190x) and EGSO (260x) at $27{ }^{\circ} \mathrm{C}$. Increasing the temperature, the values remained higher; however, the difference decrease to $85 \times$ and $18 \times$ at $40{ }^{\circ} \mathrm{C}$; $40 \times$ and $9 \times$ at $60^{\circ} \mathrm{C}$; and finally, to $24 \times$ and $7 \times$ at $80^{\circ} \mathrm{C}$.

Table 3. Viscosity values obtained for each sample at different temperatures by linear regression

\begin{tabular}{lcccc}
\hline Temperature $/{ }^{\circ} \mathrm{C}$ & 27 & 40 & 60 & 80 \\
\hline$\eta_{\mathrm{GSO}} /(\mathrm{mPa} \mathrm{s})$ & $46.02 \pm 2.8$ & $27.40 \pm 0.15$ & $15.00 \pm 0.10$ & $8.91 \pm 0.09$ \\
$\eta_{\mathrm{EGSO}} /(\mathrm{mPa} \mathrm{s})$ & $336.91 \pm 1.16$ & $128.92 \pm 0.36$ & $68.08 \pm 0.34$ & $32.54 \pm 0.70$ \\
$\eta_{\mathrm{MGSO}} /(\mathrm{mPa} \mathrm{s})$ & $8792 \pm 20.19$ & $2353.57 \pm 2.64$ & $609.03 \pm 0.53$ & $220.97 \pm 0.3$ \\
\hline
\end{tabular}

ๆ: viscosity value; GSO: grape seed oil; EGSO: epoxidized grape seed oil; MGSO: maleinized grape seed oil. 
These results support the DSC data, since only MGSO exhibited second order transitions, which are resulted from the chain alignment under heating.

\section{Conclusions}

Both grape seed oil derivatives were efficiently produced. The results from titration, MIR, and ${ }^{1} \mathrm{H}$ NMR confirmed that the epoxidation reaction was successfully performed using heterogeneous catalyst and in only $3 \mathrm{~h}$, provided conversion and yield values around $99.0 \%$. The synthesis was greener and more efficiently than those reported in literature, and the Amberlite-IR120 can be reuse at least $4 \times$ without purification, showing higher values (ca. 99.0\%) of conversion, yield, and selectivity and even after $5 \times$ using the selectivity was kept. Furthermore, the titration results show the maleinization reaction provided 1.79 mmol of anhydride per gram of sample, which were incorporated in four different ways, as confirmed by ${ }^{1} \mathrm{H}$ NMR and MIR. Moreover, by TG/DTG-DTA it was verified that the first step of mass loss was affected after the chemical modifications, as well as their thermal stability. The crystallization process was also modified due to the intermolecular interactions. These thermal analytical results agree with the viscosities values: GSO $<$ EGSO $<<<$ MGSO. Despite their different viscosity values at the same temperature, all samples exhibited Newtonian behavior; thus, they could be submitted to different flows and their viscosity kept. In addition, the temperature did not affect the Newtonian behavior of any sample; however, the viscosity values exponentially decreased when the temperature increased. Therefore, based on the characterization results, these renewable chemicals could be used as an alternative raw material to different petrochemicals industries. Finally, the development of one polymer based in both monomers here reported are in development and will be reported in a further paper.

\section{Supplementary Information}

Supplementary data (Figures S1-S14) are available free of charge at http://jbcs.sbq.org.br as PDF file.

\section{Acknowledgments}

This work was supported by São Paulo Research Foundation (FAPESP, grants numbers 2017/08820-8, 2018/03460-6, and 2020/00906-3), CAPES (grant numbers: 024/2012 Pro-equipment and 011/2009), and CNPq (grant number 301857/2018-0).

\section{Author Contributions}

Caroline Gaglieri was responsible for conceptualization, data curation, investigation, validation, visualization, writing original draft, writing-review and editing; Rafael T. Alarcon for conceptualization, investigation, validation, writing original draft, writing-review and editing; Raquel Magri for investigation, writing original draft; Aniele de Moura for investigation, visualization, writing original draft, writing-review and editing; Luiz Carlos da SilvaFilho for investigation, writing-review and editing; Gilbert Bannach for conceptualization, funding acquisition, investigation, project administration, validation, writingreview and editing.

\section{References}

1. Pérez, C.; del Castillo, M. L. R.; Gil, C.; Blanch, G. P.; Flores, G.; Food Funct. 2015, 6, 2607.

2. Dabetic, N. M.; Todorovic, V. M.; Djuricic, I. D.; Stankovic, J. A. A.; Eur. J. Lipid Sci. Technol. 2020, 122, 19000447.

3. Empresa Brasileira de Pesquisa Agropecuária (Embrapa); Vitivinicultura Brasileira: Panorama 2019; available at https:// www.embrapa.br/busca-de-publicacoes/-/publicacao/1124189/ vitivinicultura-brasileira-panorama-2019, accessed in July 2021.

4. International Organisation of Vine and Wine Intergovernmental Organisation (OIV); 2019 Statistical Report on World Vitiviniculture, available at https://www.oiv.int/public/ medias/6782/oiv-2019-statistical-report-on-world-vitiviniculture. pdf, accessed in July 2021.

5. Alarcon, R. T.; Lamb, K. J.; Bannach, G.; North, M.; ChemSusChem 2021, 14, 169.

6. Hogervorst, J. C.; Miljiic, U.; Puskas, V. In Handbook of Grape Processing By-Products; Academic Press: London, 2017.

7. Jin, B.; Kelly, J. M. In Biotechnology for Agro-Industrial Residues Utilisation; Poonam, S.-N. N.; Pandey, A., eds.; Springer: Dordrecht, 2009, p. 293.

8. Chambre, D. R.; Tociu, M.; Stanescu, M. D.; Popescu, C.; J. Sci. Food Agric. 2019, 99, 6324.

9. Dabi, M.; Saha, U. K.; J. Energy Inst. 2019, 92, 1710.

10. Lacatasu, I.; Istrati, D.; Popescu, M.; Seciu, A. M.; Panteli, L. M.; Badea, N.; Mater. Sci. Eng., B 2020, 108, 110412.

11. Doufene, K.; Lapinte, V.; Gaveau, P.; Felix, G.; Cacciaguerra, T.; Chopineau, J.; Robin, J.; Devoisselle, J.; Aubert-Pouessel, A.; Int. J. Pharm. 2019, 567, 118478.

12. Juric, S.; Juric, M.; Siddique, M. A. B.; Fathi, M.; Food Rev. Int. 2020, DOI: 10.1080/87559129.2020.1717524.

13. Bhalerao, A. S. M.; Patwardhan, A. V.; Bhosale, M. A.; Kulkarni, V. M.; Bhanage, B. M.; RSC Adv. 2016, 6, 38906.

14. Romero, S.; Minari, R. J.; Collins, S. E.; Ind. Eng. Chem. Res. 2021, 60, 5364 . 
15. Ghumman, A. S. S.; Shamsuddin, M. R.; Nasef, M. M.; Yahya, W. Z. N.; Ayoub, M.; Cheah, B.; Abbasi, A.; ChemistrySelect 2021, 6, 1180.

16. Murru, C.; Badia-Laiño, R.; Díaz-García, M. E.; ACS Sustainable Chem. Eng. 2021, 9, 1459.

17. Paraskar, P. M.; Prabhudesai, M. S.; Hatkar, V. M.; Kulkarni, R. D.; Prog. Org. Coat. 2021, 156, 106267.

18. Noè, C.; Iannucci, L.; Malburet, S.; Graillot, A.; Sangermano, M.; Grassini, S.; Macromol. Mater. Eng. 2021, 306, 2100029.

19. Xiong, G.; Xiong, W.; Dai, S.; Lin, M.; Xia, G.; Wan, X.; Mu, Y.; ACS Appl. Bio Mater. 2021, 4, 1360.

20. Park, S.; Jin, F.; Lee, J.; Macromol. Rapid Commun. 2004, 25 , 724.

21. Piccolo, D.; Vianello, C.; Lorenzetti, A.; Maschio, G.; Chem. Eng. J. 2019, 377, 120113.

22. Catalá, J.; García-Vargas, J. M.; Ramos, M. J.; Rodríguez, J. F.; García, M. T.; J. Supercrit. Fluids 2021, 168, 105070.

23. Clark, A. J.; Ross, A. H.; Bon, S. A. F.; J. Polym. Environ. 2017, 25,1 .

24. Rosu, L.; Varganici, C.; Mustata, F. R.; Rusu, T.; Rosu, D.; Rosca, I.; Tudorachi, N.; Teaca, C.; ACS Sustainable Chem. Eng. 2018, 6, 5470.

25. de Haro, J. C.; Izarra, I.; Rodriguez, J. F.; Perez, A.; Carmona, M.; J. Cleaner Prod. 2016, 138, 70.

26. Cai, X.; Zheng, J. L.; Aguilera, A. F.; Vernieres-Hassimi, L.; Tolvanen, P.; Salmi, T.; Leveneur, S.; Int. J. Chem. Kinet. 2018, $50,726$.

27. Zovi, O.; Lecamp, L.; Loutelier-Bourhis, C.; Lange, C. M.; Bunel, C.; Green Chem. 2011, 13, 1014.

28. Liu, C.; Liu, Z.; Tisserat, B. H.; Wang, R.; Shuman, T. P.; Zhou, Y.; Hu, L.; Ind. Crops Prod. 2015, 71, 185.

29. Eren, T.; Kusefoglu, S. H.; Wool, R.; J. Appl. Polym. Sci. 2003, 90, 197.

30. Stefanoiu, F.; Candy, L.; Vaca-Garcia, C.; Borredon, E.; Eur. J. Lipid Sci. Technol. 2008, 110, 441.

31. Alarcon, R. T.; Gaglieri, C.; de Souza, O. A.; Rinaldo, D.; Bannach, G.; J. Polym. Environ. 2020, 28, 1265.

32. Anastas, P.; Eghbali, N.; Chem. Soc. Rev. 2010, 39, 301.

33. Anastas, P.; Zimmerman, J. B.; Environ. Sci. Technol. 2003, 37, 94A.

34. ASTM D5554-15: Standard Test Method for Determination of The Iodine Value of Fats and Oils, ASTM International, West Conshohocken, PA, 2011.
35. ASTM D1652-11: Standard Test Method for Epoxy Content of Epoxy Resins, ASTM International, West Conshohocken, PA, 2019.

36. Guillén, M. D.; Ruiz, A.; Eur. J. Lipid Sci. Technol. 2003, 105, 688.

37. Alarcon, R. T.; Gaglieri, C.; Lamb, K. J.; North, M.; Bannach, G.; Ind. Crops Prod. 2020, 154, 112585.

38. Cai, X.; Matos, M.; Leveneur, S.; Ind. Eng. Chem. Res. 2019, $58,1548$.

39. Favero, D.; Marcon, V. R. R.; Barcellos, T.; Gomez, C. M.; Sanchis, M. J.; Carsi, M.; Figueroa, C. A.; Banchi, O.; J. Mol. Liq. 2019, 285, 136.

40. Abolins, A.; Kirpluks, M.; Vanags, E.; Fridrihsone, A.; Cabulis, U.; J. Polym. Environ. 2020, 28, 1822.

41. Kuranska, M.; Niemiec, M.; Catalysts 2020, 10, 1261.

42. Mungroo, R.; Pradhan, N. C.; Goud, V. V.; Dalai, A. K.; J. Am. Oil Chem. Soc. 2008, 85, 887.

43. Sinadinovic-Fiser, S.; Jankovic, M.; Borota, O.; Chem. Eng. Process. 2012, 62, 106.

44. Goud, V. V.; Patwardhan, A. V.; Dinda, S.; Pradhan, N. C.; Eur. J. Lipid. Sci. Technol. 2007, 109, 575.

45. Brown, T. L.; Lemay Jr., H. E.; Bursten, B. E.; Murphy, C. J.; Woodward, P. M.; Stoltzfus, M. W.; Chemistry-The Central Science, $13^{\text {th }}$ ed.; Pearson: Boston, 2015.

46. Tran, P.; Seybold, K.; Graiver, D.; Narayan, R.; J. Am. Oil Chem. Soc. 2005, 82, 189.

47. Xia, W.; Budge, S. M.; Lumsden, M. D.; J. Am. Oil Chem. Soc. 2016, 93, 467.

48. de Moura, A.; Gaglieri, C.; Alarcon, R. T.; Ferreira, P. O.; Magdalena, A. G.; Bannach, G.; Braz. J. Therm. Anal. 2017, 6, DOI: 10.18362/bjta.v6.i4.22.

49. Santos, J. C. O.; dos Santos, I. M. G.; de Souza, A. G.; Prasad, S.; dos Santos, A. V.; Food Eng. Phys. Prop. 2002, 67, 1393.

50. Cai, X.; Aissa, K. A.; Estel, L.; Leneneur, S.; J. Chem. Eng. Data 2018, 63, 1524.

51. Sahoo, S. K.; Khandelwal, V.; Manik, G.; Int. J. Adhes. Adhes. 2019, 89, 174.

52. Nik, W. S. W.; Giap, S. G. E.; Masiuk, H. H.; Senin, H. B.; Mater. Sci. Forum 2006, 517, 147.

53. Fasina, O. O.; Hallman, H.; Craig-Schmidt, M.; Clements, C.; J. Am. Oil Chem. Soc. 2006, 83, 899 .

Submitted: May 12, 2021

Published online: July 23, 2021 